\title{
Rolezão Preto: uma autoetnografia sobre o corpo negro em um centro cultural no Rio de Janeiro
}

\author{
DiONÍSIO DE ALMEIDA BRAZO \\ Universidad Federal Fluminense | Niterói, RJ, Brasil \\ dionisioalmeida@id.uff.br
}

DOI 10.11606/issn.2316-9133.v30i1pe176658

\begin{abstract}
resumo Este texto objetiva refletir sobre as formas de ocupação do corpo negro nos espaços culturais. Farei isso a partir de um exercício autoetnográfico, por meio dos sentidos e sensibilidades suscitados na minha participação em uma visita mediada a exposição de arte de um artista negro estadunidense, no Rio de Janeiro. Diante disso, a discussão do texto perpassa as lutas históricas dos negros brasileiros para transformar a ausência em presença, apontando para a utilização do "rolezinho" como ferramenta política potente na ocupação dos espaços. Tal fato me fez refletir acerca das questões subjetivas envolvidas para o acesso ou a exclusão dos corpos negros.
\end{abstract}

palavras-chave Autoetnografia. Rolezinho. Negritude. Museu.

Rolezão preto: an autoethnographic account on black bodies in a cultural centre in Rio de Janeiro

abstract This text aims to rethink on the occupation of the black body of the urban spaces. Based on an autoethnographic account, the essay focuses on the senses and sensibilities aroused the researcher's participation in a mediated visit to the art exhibition of a black American artist in Rio de Janeiro. In the face of this, the discussion t pervades the historical struggles to transform absence and presence, pointing to the use of the little roll as a powerful political tool in the occupation of spaces.

keywords Museums. Professionalization of anthropology. professional trajectories.

Rolezão preto: una autoetnografía sobre el cuerpo negro en un centro cultural de Río de Janeiro

resumen El texto reflexiona sobre las formas de ocupación del cuerpo negro en los espacios urbanos. Esto se hace desde un ejercicio autoetnográfico que, a través de los sentidos y sensibilidades levantadas la participación del investigador en una visita mediada a la exposición 
de arte de un artista negro de Estados Unidos, en Río de Janeiro. Por tanto, la discusión del texto impregna las luchas históricas por transformar la ausencia y la presencia, apuntando al uso del rolezinho como una poderosa herramienta política en la ocupación de espacios.

palabras clave Autoetnografía. Rolezinho. Negritud. Museo.

\section{Introdução}

As instituições culturais, com destaque aos museus e centros culturais, são espaços que servem como chaves de leitura do mundo que, por meio da experiência artística, permite a observação das tensões e disputas de poder da sociedade contemporânea. No entanto, essa dinâmica social também pode ser notada em relação às instituições como componentes estruturantes de uma sociedade desigual e hierarquizada, as quais parte da população não tem acesso.

Essa percepção fez com que as instituições museológicas adotassem ações de desenvolvimento de público, recebendo visitas cada vez mais amplas e heterogêneas (Godoy, 2017). Contudo, essas medidas não anulam as tensões e disputas de poder historicamente presentes nesses espaços. Se antes, na abertura das coleções principescas ao público, tínhamos regras bem delimitadas de quem poderia entrar ou não nas instituições culturais, bastantes calcadas na classe social, agora as restrições são de outra natureza.

$\mathrm{Na}$ medida em que as lutas sociais avançam pelo direito de acesso à cultura - aqui trabalhamos com os museus e centros culturais como lócus de observação -, podemos dizer que as tensões sociais, amplamente difundidas pelos veículos da mídia, voltaram à ordem do dia com as manifestações de junho de 2013 (Scherer-Warren, 2014). Naquela época, a população se mobilizou contra o aumento das passagens, que representava a fragilidade da aquisição de direitos vinculada ao consumo de bens materiais. As medidas implementadas pelos governos do Partido dos Trabalhadores (PT) mostraram-se insustentáveis, posto que o sistema capitalista forçava a aprovação de medidas contra o povo, resultando na perda de direitos.

Tendo o engajamento popular como um dos principais legados da manifestação, novas formas de organizar a indignação do povo foram surgindo. Ainda naquele ano, um dos assuntos mais comentados no país foram os "rolezinhos", ocorridos em São Paulo. Esses encontros nos shoppings, marcados pela internet por grupos de jovens da periferia, abriram novamente espaço para o debate sobre segregação social e racial.

O avanço dessa discussão fomentou novas interpretações e firmou o "rolezinho" como uma ferramenta política de apropriação dos espaços considerados da classe dominante, para além dos shoppings. Nesse contexto, o Setorial de Negritude, parte de um coletivo de juventude mais amplo, o qual faço parte, promoveu o "Rolezão Preto", que consiste em passeios feitos em torno de alguma criação cultural e/ou artística que paute a juventude negra. Neste caso relatado 
no artigo, foi uma exposição de um artista negro, nascido nos Estados Unidos da América, atravessado por questões tidas como marginais.

Assim, o objetivo deste texto é socializar reflexões a partir da minha participação no "Rolezão Preto", apontando que as tensões nesses espaços não estão resolvidas e como podemos avançar sobre esse debate. Essa vontade veio no momento que me entendi como um corpo estranho, na instituição cultural em que a visita ocorria, a partir da indignação de um homem branco que deslegitimou a fala do mediador do grupo (que utilizava linguagem periférica ${ }^{1}$ para narrar a história das obras e a vida do artista).

O momento que deveria ser de encontro, interação e troca é, então, transpassado pelo racismo $^{2}$ na tentativa de legitimar uma norma padrão de língua. Sendo o discurso uma das formas de poder exercidas pela classe dominante, como estudos de Foucault (2014) demonstraram, opto, assim, pela contra palavra por meio da autoetnografia, completando o círculo hermenêutico, apontado por Paul Ricoeur (1994).

A autoetnografia nos permite realizar uma reflexão centrada nas nossas experiências e visão de mundo. De acordo com Santos (2017),

Isso evidencia que a reflexividade assume um papel muito importante no modelo de investigação autoetnográfico, haja vista que a reflexividade impõe a constante conscientização, avaliação e reavaliação feita pelo pesquisador da sua própria contribuição/influência/forma da pesquisa intersubjetiva e os resultados consequentes da sua investigação (Santos, 2017: 218).

De tal modo, assumo a subjetividade do texto e o meu lugar de fala. Isto é, as sensibilidades que me afetam e perpassam este texto são de um corpo negro, masculino, morador da Zona Norte do Rio de Janeiro, na divisa com a Baixada Fluminense e pesquisador da área cultural, formado em Turismo.

Sempre fui aluno de instituições públicas de ensino, tendo pouco contato com espaços de cultura. O meu interesse por museus e centros culturais só surgiu, na universidade, durante o primeiro período, quando tive aula de História da Arte. Assim, orientei meus estudos e

\footnotetext{
${ }^{1}$ Linguagem periférica é entendida, aqui, como uma ferramenta política que visa traduzir o conteúdo acadêmico ou hermético para um público mais amplo marcado por questões periféricas.

2 Ao longo do texto, aponto o racismo como uma das manifestações de hostilidade presentes nas instituições culturais. Isso se deve não para diminuir a profundidade e seus efeitos nos corpos negros, mas para denunciar que, dentro das relações de hostilidade, o racismo pode estar presente nas interações sociais, e, frequentemente, não é dada a devida atenção
} 
pesquisas para os aspectos socioculturais do turismo ${ }^{3}$, e, mais tarde, virei monitor da disciplina. Perceber a baixa produção acadêmica no turismo que problematizem a realidade, parecendo tudo tão harmônico, também me impulsiona a escrever este texto.

Ao passo em que a sociedade foi se transformando com os debates de raça, classe, gênero e sexualidade, pude sensibilizar o meu olhar para algumas questões que, até então, não percebia. Os discursos em que estava inserido versavam sobre a representatividade de outros corpos e narrativas dentro dos espaços culturais, mas, à medida que essas histórias eram contadas, motivavam outros públicos a também conhecê-los.

Esse foi o caso da minha experiência na exposição de um artista negro estadunidense que, mesmo com todos os de história de vida, era uma representatividade para uma juventude preta e periférica. Nesse sentido, a nossa opção metodológica serve também para fazermos frente à branquitude ${ }^{4}$, dimensionando as opressões que corpos negros sofrem diariamente. Voltaremos a abordar sobre o assunto na seção correspondente.

Este texto está dividido em cinco partes, além da Introdução. Na próxima seção, fizemos alguns apontamentos metodológicos a respeito da autoetnografia empregada neste estudo. Em seguida, analisamos como se configurou o racismo estrutural no Brasil e algumas das estratégias traçadas pelo Movimento Negro. Na terceira parte, realizamos uma breve contextualização sobre o surgimento dos "rolezinhos", como uma herança dos movimentos políticos do ano de 2013. No quarto segmento, abordamos a minha experiência na visita da exposição artística. Ao final, tecemos algumas considerações sobre a visitação e o uso do "rolezinho" como ferramenta potente para estimular o acesso às instituições culturais.

\section{Nota metodológica sobre este exercício autoetnográfico}

Do ponto de vista metodológico, este trabalho caracteriza-se como um estudo qualitativo, feito mediante pesquisa bibliográfica dos temas debatidos e inspirada na autoetnografia. $^{5}$

No entanto, antes de prosseguirmos, cabe destacar que não há consenso sobre o que é uma autoetnografia. Gama (2020) explica que para alguns autores esse termo é entendido como

\footnotetext{
${ }^{3}$ Cabe evidenciar que o campo do turismo não trata apenas de "turistas", mas do fenômeno no seu sentido mais amplo, contemplando também pesquisas voltadas para os moradores das cidades.

${ }^{4}$ Segundo Cardoso (2014, p. 100), "o termo branquitude é o mais utilizado pelos pesquisadores para se referir à identidade branca, ou se preferirem, a identidade racial do branco". Para o autor, podemos distinguir a branquitude em dois grupos: 1) a branquitude crítica, aqueles que têm consciência do racismo e o desaprovam publicamente, como os que compõem grupos antirracistas; e 2) a branquitude acrítica, que se pauta em uma superioridade racial inerente à identidade branca. No entanto, neste trabalho, decidimos pelo não aprofundamento dessas distinções por entendermos que ambos os grupos são beneficiados estruturalmente, além de extrapolar os limites deste texto. 5 Segundo Santos (2017, p. 218) “Autoetnografia” vem do grego: auto (self = "em si mesmo”), ethnos (nação = no sentido de "um povo ou grupo de pertencimento") e grapho (escrever = "a forma de construção da escrita”)".
} 
um gênero textual, um conceito em formulação, e para outros um método. De acordo com os autores utilizados, compreendemos a autoetnografia como um procedimento empregado para descrever uma forma particular de construção de um relato sobre um grupo cultural centrado “em si mesmo" (Santos, 2017).

Santos (2017), fundamentado em Chang (2008), expõe que esse método é sustentado pelo modelo triádico, baseado em três orientações.

A primeira seria uma orientação metodológica - cuja base é etnográfica e analítica; a segunda, por uma orientação cultural - cuja base é a interpretação: a) dos fatores vividos (a partir da memória), b) do aspecto relacional entre o pesquisador e os sujeitos (e objetos) da pesquisa e c) dos fenômenos sociais investigados; e por último, a orientação do conteúdo - cuja base é a autobiografia aliada a um caráter reflexivo (Santos, 2017: 218 grifos nossos).

Ainda segundo o autor, a principal característica desse método é a centralidade dada às experiências pessoais do pesquisador, na qual a sua subjetividade representa uma posição política frente ao tema e influencia as suas escolhas. Nesse sentido, Gama (2020) contribui afirmando que a autoetnografia pode ser potente ao revelar o não dito, advogar contra a invisibilidade e os silenciamentos, ressaltando a importância da narração pessoal nas ciências sociais e humanas.

Esse é o primeiro propósito, descrito por Adam, Ellis e Jones (2017), para se realizar a autoetnografia. Os teóricos explicam que a experiência pessoal é utilizada para complementar ou preencher lacunas existentes nas pesquisas, - como apontamos brevemente na Introdução deste trabalho. Isso ocorre porque refletimos sobre uma experiência apreendida por intermédio do corpo que marca presença, configura novos espaços, experimenta emoções, dentre outros sentidos (Gama, 2017).

O segundo objetivo da autoetnografia, conforme esses autores, é articular o conhecimento interno da experiência, revelando aspectos que outros pesquisadores podem não conhecer, ou, como no caso deste texto, uma sensibilidade que não é afetada por determinados corpos. Contudo, eles alertam que o conhecimento privilegiado de opressões institucionais, por exemplo, não significa um conhecimento mais verdadeiro ou preciso do que de outros. A nosso ver, esse aspecto é interessante na medida em que novos corpos ocupam espaço na academia, volta-se a autoridade de fala/escrita para sujeitos que antes eram os "objetos de pesquisa" e agora podem falar da sua experiência, inclusive em primeira pessoa.

A voz, utilizada nos textos autoetnográficos, é outro aspecto relevante e, por vezes, lançamos mão neste texto, além da primeira pessoa do plural ("nós"). É comum a utilização da primeira pessoa do singular ("eu") para descrever as experiências, o ponto de vista observado do pesquisador. Além do emprego da segunda voz do singular ("tu" ou "você"), convidando o leitor 
a participar do texto, e da terceira pessoa do singular ou plural ("ele" ou "eles") para descrever ações feitas por outros personagens do campo (Santos, 2017).

Esse papel (político) leva Adam, Ellis e Jones (2017) a afirmarem: "o objetivo final da autoetnografia é criar textos acessíveis a públicos maiores, principalmente públicos fora dos ambientes acadêmicos" (Adam; Ellis; Jones, 2017: 04). ${ }^{6}$

Além disso, Santos (2017) aponta mais duas características, afora o uso da experiência pessoal do pesquisador. A primeira é que a autoetnografia reconhece e valoriza a relação do pesquisador com outros interlocutores da pesquisa, o que pode apresentar as vulnerabilidades, emoções e ambiguidades do campo, e contrasta diretamente com a percepção positivista da pesquisa científica (que assume a necessidade de separação do objeto e pesquisador). E, por último, é um método que exige profunda autorreflexão (ou reflexividade), no sentido de entender tanto o pessoal quanto o social; o micro e o macro.

Evidencia-se, portanto, que este estudo é fruto de uma experiência (e não de "dados" de pesquisa) em um centro cultural do Rio de Janeiro, mencionado na introdução, em que o corpo e a emoção do pesquisador foram convidados a refletir sobre a ocupação daquele espaço.

A seguir, discutiremos brevemente sobre os motivos históricos que provocam a ausência de corpos negros em espaços sociais no Brasil e as estratégias com vistas a diminuir a desigualdade.

\section{Sobre a ausência de Corpos Negros nos Espaços Sociais}

Em uma sociedade fundada sob o mito das três raças, abordar a formação da identidade negra é inserir na ordem do dia as mais diversas práticas de discriminação, como também de resistência desenvolvidas pelo povo preto ao longo da história. Tal mito preconizava a harmonia das relações entre negros e brancos, em que o pardo, seria a resposta dessa crença. No entanto, expõe Gonzalez (1984), “[...] todo mito, oculta algo para além daquilo que mostra” (Gonzalez, 1984: 228 apud Catoia, 2018: 36). Da Matta (1986) corrobora com a autora ao afirmar que o mito é uma forma "[...] sutil de esconder uma sociedade que ainda não se sabe hierarquizada e dividida entre múltiplas possibilidades de classificação" (DaMatta, 1986: 48).

A partir da publicação de Antonil (1711), Da Matta (1984) descreve como foi forjado o "racismo à brasileira”. Antonil (1711) narrava o Brasil como o inferno para os negros, purgatório para os brancos e um paraíso para os pardos. ${ }^{7}$ Essa associação ao paraíso deve-se pela concepção intermediária entre brancos e negros, em que o pardo seria a síntese das acepções positivas em termos raciais. No entanto, Da Matta (1984) ressalta que, entre os dois limites (branco e negro), existem inúmeras categorias intermediárias que são absorvidas por essas duas.

\footnotetext{
${ }^{6}$ Todas as traduções de citações em língua estrangeira, quando não mencionadas a autoria, foram realizadas de forma livre pelo autor. Texto original: "A final goal of autoethnography is to create texts that are accessible to larger audiences, primarily audiences outside of academic settings" (Adam; Lewis; Jones, 2017:4)

${ }^{7}$ Embora o autor utilize o termo mulato, ao longo do texto empregaremos o termo pardo.
} 
O "racismo à brasileira" seria, então, mais contextualizado e sofisticado quando comparado ao de países como os Estados Unidos da América, onde o racismo era sinônimo de segregação. $\mathrm{O}$ mito das três raças propagou-se no imaginário social brasileiro, como se o negro de pele mais clara e o pardo fossem aceitos e tivessem mais condições de superar a história escravocrata; negando o fato de que essa miscigenação tenha sido feita mediante a violência sexual da mulher africana escravizada e da mulher indígena e dos incentivos para a imigração de povos europeus.

A narrativa do pardo como algo positivo e prova de uma sociedade não hierarquizada ficou em maior evidência com a publicação do livro Casa Grande e Senzala, de Gilberto Freyre, em 1933. Nessa publicação, o autor afirma que a "relação harmônica" entre brancos e negros seria "[...] responsável pela diminuição de antagonismos sociais e por uma democracia racial" (Catoia, 2018: 35). O discurso da democracia racial tomou maior consistência durante o Estado Novo (1937-1945) ${ }^{8}$, quando, por meio de políticas públicas, elementos culturais da população negra foram integrados aos símbolos nacionais, dando início ao projeto político, denominado por Machado (2002), de "mestiçagem arqueológica”.

De acordo com o pensador, esse projeto pretendia não negar a história, mas dispô-la em um passado arqueológico, que só pode ser acessado a partir de reinterpretações. Isso permitiu que toda a disputa fosse fixada no passado, tornando o presente harmônico e resolvido. Catoia (2018) aponta para uma nacionalidade imaginada em que

[...] são valorizadas as contribuições de povos que aparentemente "se perderam" na história após terem colaborado para a formação do país, sem levar em conta sua continuidade com o presente, pois a mestiçagem arqueológica pressupõe que a mestiçagem já foi realizada no passado e os conflitos por ela gerados já foram resolvidos no presente (Catoia, 2018: 35).

Ao elevar à categoria de símbolos nacionais alguns elementos da cultura negra, o Estado brasileiro reafirma o que era e não era permitido. Por exemplo, ao mesmo tempo que transformava a capoeira em modalidade esportiva e subvencionava o carnaval como representação nacional, impedia a organização política do movimento social negro (Catoia, 2018).

[...] nossa identidade nacional, construída a partir do mito de democracia racial, precisava aniquilar o corpo negro e indígena e, ao mesmo tempo,

\footnotetext{
${ }^{8}$ Terceira e última fase da Era Vargas (1930-1945), período em que Getúlio Vargas comandou o Brasil. O Estado Novo foi um regime político, implementado após um golpe de Estado, no qual mantinha uma aproximação com os ideais nazifascistas europeus, em voga na época. Como características podemos apontar a centralização do poder, o autoritarismo e o anticomunismo.
} 
ocultar discursivamente os conflitos e as diferenças étnicas, culturais, religiosas e sociais existentes no interior do Estado brasileiro, nos projetando, assim, como uma nação harmônica e democrática (Catoia, 2018: 36).

Vários níveis e estratégias de dominação foram desenvolvidos para que a composição estrutural da sociedade brasileira se mantivesse hierárquica e discriminatória. Uma delas foi o estímulo à imigração de europeus para o país no pós-abolição, em detrimento da reparação de direitos para a população negra (o que a distanciou ainda mais do alcance a melhores condições de vida e trabalho). O período Vargas (1930-1945) regulava a entrada de imigrantes de acordo com interesses do país, a partir do Decreto-Lei 7967/1945 - que dispõe sobre a imigração e colonização. No capítulo I sobre a admissão de estrangeiros, uma das condições para entrar no Brasil, conforme o artigo segundo, seria “[a] necessidade de preservar e desenvolver a composição étnica da população - as características mais desejáveis de sua antecedência europeia (sic)" (Brasil, 1945).

Sistemáticos atos de exclusão da população negra, como o processo eugenista da saúde, da educação e da migração conduzido pelo Estado, sustenta o racismo institucional que contribui para a naturalização e a reprodução da desigualdade racial. Pois, como afirma Catoia (2018), acreditava-se que a desigualdade social estava atrelada somente à de classe, sendo esse o argumento para a ausência de qualquer legislação antirracista. Tal fato torna mais complexo o combate à discriminação racial, uma vez que se desenvolveu nos brasileiros o preconceito de ter preconceito, como afirmou Florestan Fernandes (DaMatta, 1986).

Isso tornou possível que, no imaginário social brasileiro, as conquistas e, principalmente, as derrotas do povo negro fossem individualizadas sob a falácia de que todos os indivíduos teriam as mesmas oportunidades. Que seria apenas uma questão de querer, entretanto, desconsidera todo o processo histórico de exclusão aos sistemas de ensino, trabalho e renda. Em uma sociedade construída sob o ethos da branquitude, estabelecer a meritocracia a pretexto de que todos temos as mesmas oportunidades de atingir nossos objetivos é naturalizar e reproduzir a discriminação racial, uma vez que a estrutura brasileira foi forjada para rejeitar o corpo negro em todos os espaços sociais.

A luta por uma legislação antirracista ganhou maior destaque durante as décadas de 1940 e 1950, quando o Movimento Negro debatia o processo de subalternização da população negra, ao evidenciar o racismo como gerador de desigualdade. A luta política do movimento negro teve, portanto, centralidade para explicitar a confluência entre desigualdade socioeconômica e desigualdade racial, bem como para evidenciar que a dimensão econômica explica apenas parte da desigualdade histórica entre brancos e negros no 
Brasil, denunciando, assim, a outra parte explicada pelo racismo, pela discriminação racial e pelo racismo institucional legitimado historicamente pelo Estado brasileiro (Catoia, 2018: 47).

Nesse momento, o Movimento Negro começava a disputar o espaço sobre as narrativas produzidas acerca da população negra. A tática era evidenciar os discursos que negavam o racismo, para, então, avançar nos debates pela conquista de direitos, legislação e políticas públicas contra os efeitos da desigualdade, assim como disputar os sentidos de nação e identidade negra.

Com o acúmulo da luta antirracista durante esses anos, por parte de diversas organizações culturais e políticas, em meio à Ditadura Militar (1964-1985), surge o Movimento Negro Unificado Contra a Discriminação Racial (MNUCDR), em 1978 - no ano seguinte passa a ser chamado Movimento Negro Unificado (MNU). ${ }^{9}$ O movimento existe até os dias atuais, em vários estados, e, segundo Pereira (2010), a sua criação parecia um caminho inevitável, tendo em vista sua articulação com outras iniciativas sociais no combate ao racismo.

A partir da década de 1980, aponta Pereira (2010), ativistas negros buscavam maior articulação com os poderes públicos, com destaque ao Executivo e ao Legislativo, o que ocasionou a criação de órgãos governamentais para tratar de questões relacionadas à população negra. Essa interlocução com o governo veio por intermédio de vitoriosas candidaturas nas instâncias estaduais, em 1982, opositoras ao regime militar em estados, como Rio de Janeiro e São Paulo. Ainda que tivessem surgido críticas dentro do próprio Movimento Negro, em especial do setor mais radical, a aproximação com a esfera pública se tornou cada vez mais próxima.

Com o movimento das "Diretas Já" $(1984)^{10}$ e o fim do bipartidarismo, militantes do movimento participaram da organização e fundação de partidos políticos, como o Partido dos Trabalhadores (PT). Contudo, prevalecia a luta de classes em detrimento da luta racial. O tema não era considerado pertinente nos partidos de esquerda, com exceção do Partido Democrático Trabalhista (PDT). Abdias do Nascimento, junto com Brizola, e outros políticos participaram da fundação do PDT, tendo, desde o seu documento de fundação, o compromisso com a pauta racial, sendo posteriormente reforçado pelo Estatuto do Partido.

\footnotetext{
${ }^{9}$ O Movimento Negro Unificado (MNU) é, notadamente, uma importante organização na luta do povo negro no Brasil. Como destaque de suas ações, podemos apontar a contribuição na formulação da Constituição de 1988. Mais informações podem ser lidas na matéria disponível no seguinte endereço eletrônico: https://www.brasildefato.com.br/2019/04/05/uma-historia-oral-do-movimento-negro-unificado-por-tres-deseus-fundadores. Acesso em: 13 jun. 2021.

${ }^{10}$ Movimento popular realizado durante a Ditadura Militar (1964-1985) no Brasil, com o objetivo de reivindicar a retomada das eleições diretas para presidente.
} 
Nesse momento, ocorreram diversos eventos e mobilizações, particularmente em 1986, por conta das eleições da Assembleia Nacional Constituinte, para que a causa racial estivesse presente na Constituição de 1988. A Convenção Nacional organizada pelo MNU, em 1986, não deixou dúvidas acerca das pautas a serem inseridas na Constituição: criminalização do racismo e regularização das terras quilombolas.

Sem dúvidas, a transformação de demandas sociais em instrumentos legais é uma importante vitória do Movimento Negro, mas não garantiu, necessariamente, suas implementações. No ano da Promulgação da Constituição de 1988, completava o centenário da Abolição da Escravatura e foi realizado, sob o título de "Marcha Contra a Farsa da Abolição", o principal ato de comemoração, no Rio de Janeiro - e o cartaz de divulgação anunciava "Nada mudou - Vamos mudar".

Durante a década de 1990, observa-se o surgimento de várias Organizações nãoGovernamentais (ONGs) voltadas para o atendimento das demandas da população negra em todo o país. Essas instituições foram cruciais para realizar ações e debater temas referentes ao assunto de modo mais aprofundado, como a saúde da mulher negra, a defesa dos direitos humanos, o racismo e a educação e a criação dos pré-vestibulares (PEREIRA, 2010). Para tal, a constante interlocução com diversos setores da sociedade brasileira e internacional foram desenvolvidas, assim como mecanismos de participação governamental em diversas instâncias, como na Conferência de Durban, em 2001. ${ }^{11}$

Assim, a conjuntura nacional leva à vitória do PT nas eleições presidenciais de 2003 e à posse de Luís Inácio Lula da Silva como chefe do Poder Executivo. A partir de então, houve uma pressão por um ritmo mais acelerado para a absorção da agenda antirracista do Movimento Negro brasileiro. É necessário salientar que a década de 1990 foi decisiva na mudança de suas ações, deslocando-se do campo da denúncia para a relação mais propositiva com os aparatos institucionais do governo.

No entanto, afirmam Machado e Rodrigues (2015), ainda que tenha se ampliado o debate sobre as minorias, as conferências nacionais de promoção da igualdade racial tiveram um caráter consultivo, e não deliberativo. Isso mostra a fragilidade da influência na agenda política governamental dos militantes antirracistas, uma vez que as decisões não precisam ser, obrigatoriamente, acolhidas pelo Estado.

Apesar disso, o "período Lula" é reconhecidamente um governo que “[...] passa a mobilizar e assimilar identidades "minoritárias" em seu leque de investimentos, alianças

\footnotetext{
11 Também conhecida como Conferência Mundial contra o Racismo, a Discriminação Racial, a Xenofobia e as Formas Conexas de Intolerância, realizada pela Organização das Nações Unidas (ONU), instituiu uma agenda mundial no combate ao racismo e outras formas de discriminação racial. Disponível em: https://brazil.unfpa.org/pt-br/conferencia-de-durban. Acesso em: 13 jun. 2021
} 
estratégicas e coalizões partidárias" (Machado; Rodrigues, 2015: 36) - transformando-se em uma característica do governo petista, prontamente seguida por Dilma Rousseff. ${ }^{12}$

Não podemos deixar de observar que o maior avanço em relação às pautas da negritude nesse período foi a implementação das ações afirmativas ${ }^{13}$ para acesso ao ensino superior, principal bandeira do Movimento Negro apresentada em Durban. Assim, houve um significativo aumento nesse aspecto, com a criação de novas vagas para atender às ações afirmativas mediante a Reestruturação e Expansão das Universidades Federais (REUNI). ${ }^{14}$

No entanto, com o acirramento da crise econômica iniciada em 2008, medidas impopulares foram tomadas pelo governo Dilma, culminando em diversos atos que, incialmente, denunciavam a fragilidade de atrelar os direitos ao poder aquisitivo. $\mathrm{O}$ aumento da passagem aprovado naquele ano acarretou grandes manifestações organizadas pelo Movimento Passe Livre (MPL), que reivindicava o acesso e uso da cidade, denunciando, mais uma vez, a segregação socioespacial. Logo, foram acrescentadas outras pautas, como educação e saúde, que foram absorvidas pela esquerda.

\section{Movimento Passe Livre e a Ascensão dos Rolezinhos}

O Movimento Passe Livre (MPL) acontece em um contexto de crise econômica causada pelo sistema capitalista mundial, que atinge o Brasil de forma mais dura em 2013. Nesse momento, atos não populares impostos pelo governo para garantir estabilidade são tomados, simultaneamente, com a aprovação de gastos milionários para a realização de megaeventos esportivos, como a Copa do Mundo (2014) e as Olimpíadas (2016).

É importante evidenciar que o MPL já tinha articulação nacional em meados dos anos 2000. A movimentação pelo passe livre foi uma estratégia relevante, no entanto, não era restrita a ele, mas, sim, à defesa do acesso à cidade em seu sentido mais amplo e em uma mudança sistêmica ao acesso aos direitos fundamentais (Scherer-Warren, 2014). ${ }^{15}$

\footnotetext{
12 Presidenta do país entre os anos de 2011 e 2016, quando, durante o seu segundo mandato, sofreu um processo de Impeachment/golpe, tirando-a do cargo.

${ }^{13}$ As ações afirmativas são um conjunto de políticas voltadas para grupos discriminados e/ou excluídos social e historicamente, oferecendo formas de compensação da desvantagem, obtidas devido ao racismo ou outros modos de discriminação. Para saber mais, acesse: https://www.geledes.org.br/politicas-de-acao-afirmativa-em-beneficioda-populacao-negra-no-brasil-um-ponto-de-vista-em-defesa-de-cotas/. Acesso em: 13 jun. 2021.

${ }^{14}$ O REUNI foi um programa de expansão da educação superior, instituído pelo Decreto no 6.096, de 24 de abril de 2007, no qual "o governo federal adotou uma série de medidas para retomar o crescimento do ensino superior público, criando condições para que as universidades federais promovam a expansão física, acadêmica e pedagógica da rede federal de educação superior”. Citação retirada da página eletrônica do REUNI, disponível em: http://reuni.mec.gov.br/o-que-e-o-reuni. Acesso em: 13 jun. 2021.

${ }^{15}$ Direitos fundamentais são aqueles inerentes ao ser humano e previstos na Constituição de 1988, como o direito à vida, à igualdade, entre outros. A título de explicação, o que diferencia um direito fundamental de um direito
} 
Em junho de 2013, as manifestações tomaram grandes proporções em resposta à repressão policial ocorrida ${ }^{16}$ em São Paulo. De acordo com Scherer-Warren (2014),

[...] o repúdio à repressão legitimada pelo Estado, por um lado, e a solidariedade à liberdade de expressão da cidadania, por outro, formaram o mote para a ampliação das manifestações em todo o país. O direito ao exercício da cidadania, da voz e da opinião pública a partir do povo propriamente dito era o que estava em jogo. Esse foi um sentimento que se transformou numa articulação discursiva de defesa da participação cidadã, num sentido excessivamente genérico, estimulado através de um discurso mediático de longo alcance, mas de pouco aprofundamento. $\mathrm{O}$ resultado foi o aumento exponencial do número de participantes e a multiplicação, em vários territórios urbanos, de manifestações autônomas, expressando solidariedades, mas também, frequentemente, antagonismos verbais e, às vezes, físicos entre subgrupos, devido à expressão de alinhamentos políticos e (ou) partidários em disputa (Scherer-Warren, 2014: 419).

É nesse contexto que os "rolezinhos", e suas variações, se tornaram um fenômeno da juventude urbana marginalizada. Como um fenômeno coletivo, social, urbano e de classe do pós-junho de 2013, percebido, primeiramente, em São Paulo, em que corpos marginalizados da cidade dão um "rolé" (na gíria carioca ou "rolê", na gíria paulista), um passeio (e daí o nome), por espaços onde a sua presença é rejeitada (Viana, 2014; Caldeira, 2014).

$\mathrm{Na}$ época em que foi observado, o "rolezinho" chamou atenção e preocupação do governo, da classe capitalista e da grande imprensa, como aponta Viana (2014). O encontro, geralmente formado na internet, é uma reação e reafirmação da juventude periférica em se legitimar nos espaços públicos.

Viana (2014) afirma que a prática não tinha grandes objetivos subversivos e políticos, ainda que a existência dessa prática seja dada por conta do reconhecimento da divisão de classe e das desigualdades raciais e problemas sociais existentes no Brasil. Para o autor, os integrantes do grupo se perdem ao assimilar os valores de consumo da elite. Logo, em sua visão, não se poderia apontar para a superação do capitalismo, pois seria uma reafirmação dele. No entanto,

\footnotetext{
humano é o plano em que estão consagrados, sendo o primeiro positivado na legislação, como a Constituição, e o segundo no plano internacional

16 Trata-se da manifestação realizada no dia 13 de junho, com cerca de 10 mil pessoas na rua. Essa ação ganhou destaque entre as manifestações que vinham sendo realizadas pelo Movimento Passe Livre, por conta da forte repressão policial. Para mais informações, acesse: https://www.cartacapital.com.br/politica/13-de-junho-o-diaque-nao-terminou-6634/. Acesso em: 14 jun. 2021.
} 
o encontro cria o conflito, desenvolvendo a consciência de classe e corroendo os valores dominantes.

$\mathrm{Na}$ análise de Caldeira (2014), a assimilação dos valores dominantes produz uma rearticulação, trazendo algumas novidades no sentido de visibilizar a sua produção cultural ao se apropriar do espaço por meio da sua presença perturbando a ordem, pois o consumo, a circulação, tensões de classe e de raça sempre foram parte do meio social na disputa pelo controle do urbano.

Dialogando com Bourdieu (1989), podemos inferir que o "rolezinho" é um instrumento criado pelas juventudes periféricas para responder às diversas violências simbólicas, que as atravessaram durante sua trajetória de vida. Sendo assim, cria-se um habitus, isto é, uma grade de leitura da vida social que retoma a capacidade produtora dos indivíduos, ao estabeleceram estratégias de luta e movimentando com a estrutura social.

É, de acordo com esse entendimento, que, ao decorrer dos anos, novas configurações e apropriações por parte dos movimentos políticos foram feitas do "rolezinho", na tentativa de superar essas críticas e direcioná-las para o foco de interesse de cada movimento. Nesse bojo, encontra-se o "Rolezão Preto", promovido pelo Setorial de Negritude, prevê balançar a ordem hegemônica. Esse processo ocorre não apenas promovendo a ocupação de corpos negros em espaços considerados da classe dominante, mas também incentivando uma reflexão acerca de temas pertinentes da e para a negritude e, em grande parte, para ver produções culturais relativas a ela, como será apresentado a seguir.

\section{Rolezão Preto}

O convite para participar do "Rolezão Preto" surgiu por eu ser um militante regular do Setorial de Negritude, que estava organizando a atividade. Esse setorial entende o acesso à cidade como um direito e considerou o "rolezinho" um instrumento potente no processo de apropriação dos espaços públicos por parte dos militantes, expondo as dinâmicas de inclusão/exclusão dos corpos pretos e atuando de forma propositiva.

O início da mediação começou por volta das 14 horas, ainda no térreo do referido centro cultural, local onde os mediadores pediram para que nos apresentássemos com nome, idade e, além disso, gênero musical mais ouvido - algumas pessoas também pontuaram o local de residência. Esse é um método pedagógico muito comum nesses encontros, pois promove a troca de informações e de saberes, entendendo o público visitante.

Devo assumir que não conhecia, até então, o artista e as obras expostas e, mesmo com o convite, não pesquisei mais informações. Tudo o que sabia me fora passado pelos organizadores e mediadores do evento, o que me permitiu ser afetado pela experiência estética. Dessa forma, a pergunta sobre o gênero musical me chamou atenção e pude perceber que existia uma diversidade no grupo que estava, com pessoas que ouviam música pop, música popular 
brasileira, samba, mas também forró, maracatu e que algumas estavam naquele espaço pela primeira vez.

Nesse debate, é importante estarmos atentos para não cairmos na falácia do "negro único". ${ }^{17}$ Embora seja um grupo formado por pessoas negras e visitando a exposição de um artista negro, que teve fortes influências do jazz, cada um tem sua subjetividade e construção de si mesmo.

Após essa rodada de apresentação, um pouco longa, pois o grupo deveria ter em torno de 20 a 30 pessoas, o mediador Ronaldo ${ }^{18}$ compara dois painéis: no primeiro, havia um grafite em um muro e, no segundo, uma pichação em um metrô. Com isso, iniciou a narração da vida do artista e as influências que atravessaram suas obras.

Observei com bastante interesse a escolha de início da mediação e o debate feito sobre o grafite e pichação com o "rolezinho". Caldeira (2014) dispõe que:

Apesar de a lógica ser conhecida, e evidente que as rearticulações recentes produzidas pelos jovens das periferias trazem novidades importantes. A circulação desses rapazes e sua produção cultural permaneceram invisíveis durante as décadas em que aconteciam sobretudo entre os bairros das periferias. Mas o grafite, a pixação ( sic) e agora os rolezinhos rompem essa invisibilidade. A pichação (sic) está por toda parte, em qualquer área da cidade (Caldeira, 2014: 15).

O mediador sabia que éramos de um Setorial de Negritude, parte de um coletivo mais amplo de juventude, e estávamos realizando um "rolezinho". Desse modo, conhecer a configuração do público-alvo torna-se uma ferramenta potente para aproximar os discursos, visto que os debates estavam difusos por toda a sociedade na época e não poderiam ser deixados de lado.

Há de se destacar, também, a presença de elementos que sempre causaram certo desconforto nos espaços artísticos: a pichação, e sua histórica desvalorização como elemento artístico cultural de uma parcela da população, mas que encontrou no grafite a sua versão mais aceitável, mais popular; e o "rolezinho" de um grupo de jovens negros(as), que, como mencionado, não fosse por essa ferramenta política, não estariam ali.

\footnotetext{
17 Esse termo aceita dois sentidos comumente utilizados em movimentos sociais de negritude. O primeiro, e mais literal, é aquele que se refere ao negro como sendo o único em um grupo rodeado de brancos. O segundo sentido, e o empregado no texto, é aquele que reduz toda a subjetividade dos negros e das negras em um estereótipo, que fecha sentido, como Bhabha (1998) mostrou.

${ }^{18}$ Nome fictício para fins de preservação do profissional.
} 
Subimos as escadas e, devido à lotação do salão expositivo, fomos para uma sala multimídia, local onde ouvimos músicas que dialogavam diretamente com a exposição, a vida do artista e, de modo mais amplo, a vida dos negros dos Estados Unidos da América e, também, do Brasil. Ouvimos Nina Simone, Jay-Z, Baco Exu do Blues, BK, Racionais, só para citar alguns músicos negros, e discutimos a relação do negro na sociedade dos anos 1980 e seu reflexo na atualidade.

A exposição estava tão lotada que precisamos entrar pela passagem de saída, evitando, assim, algum problema com os visitantes que ainda aguardavam do lado de fora. Com o encerramento do evento, jornais da época apontaram que o sucesso foi expressivo, com mais de 300 mil visitantes somente na cidade do Rio de Janeiro.

Após Ronaldo ser advertido pela controladora de lotação da sala que teria de se apressar por conta da fila de espera do lado de fora, sintetizou a história da primeira sala nos dez minutos disponibilizados por ela. Ao avançar, comecei a prestar atenção em outros aspectos e um não poderia passar despercebido, pois, por mais que já conhecesse, causou-me um sabor amargo na boca: aquele espaço estava majoritariamente ocupado por pessoas brancas.

Há todo um debate acadêmico e social sobre o acesso às instituições culturais relacionado aos capitais cultural e econômico, em termos bourdesianos, como fatores decisivos. A Pesquisa do Perfil Cultural dos Cariocas (2018) mostrou, inclusive, que a escolaridade é fundamental para o interesse pela cultura, mesmo entre aqueles de mesma renda ou classe econômica. Em relação à cor da pele, pretos e pardos representam, respectivamente, $29 \%$ e $31 \%$ das pessoas que nunca foram ao museu; se olharmos as exposições de arte, esse dado se alarga para $44 \%$ e $52 \%$ para pretos e pardos. ${ }^{19}$

Então, era de se esperar que esse seria o cenário aberto para mim. Na medida em que a mediação ocorria, atentei-me ao modo como Ronaldo falava. Era um de nós. Falava da gente, para a gente. Gesticulava como os "manos" do rap, usava uma camisa extremamente larga como eles - da própria instituição - e não poupava gírias e palavras não usuais nesses espaços para compor seu discurso. Narrava a história de obras, como a de uma representação de Jesus, apresentada como era feito no Renascimento, só que africanizado, um "Jesus Exu”. Além de dialogar com a vida do artista, a cultura pop e outras curiosidades, o que ofereceu uma reinterpretação do mundo, mediada pelas obras e centrada em matrizes africanas.

Cada obra, cada explicação de Ronaldo me fazia refletir em um outro espaço museal, outra forma de mediar e de pensar, inclusive, para minha própria formação. Admito que não fui uma das pessoas que estava lá na frente ouvindo e prestando atenção em tudo, porque o grupo

19 Dados disponíveis em: http://www.culturanorio.com.br/wp-content/ uploads/2016/07/MESA_1_ MUSEUS.pdf. Acesso em: 24 out. 2020. 
era grande e se tornou ainda maior no prosseguimento da exposição, já que outros somaram-se ao grupo.

Um momento que me chamou muita atenção e que despertou meu olhar ao entorno foi que Ronaldo se referiu ao artista como "moleque”, mas não em um tom pejorativo, e sim como usualmente costumamos nos chamar. Isso quebrou a bolha de estar entre os meus iguais, que nem sequer mudaram de afeição com a palavra, e percebi a hostilidade, elemento sempre latente nos espaços museológicos desde o seu nascedouro, como explicou Godoy (2017).

Um senhor branco, aparentemente em torno de 50 anos, prontamente retrucou nosso mediador. A rispidez daquele homem quando gritou do meu lado "Moleque. Olha como ele fala dele (se referindo ao artista): moleque", e saiu andando com seu celular na mão, enquanto tirava fotos. Admito que tive vontade de conversar com ele sobre aquilo, contudo optei por não interferir e, uma vez quebrada minha bolha, reparar ao redor e começar a pensar na vida, na sociedade, no centro cultural.

Moleque é uma forma de tratamento ao filho pequeno ou garoto, em quimbundo, uma das línguas oficiais da Angola, que, durante o período escravocrata, convencionou-se a chamar somente os filhos dos negros escravizados. A partir disso, a representação de um moleque foi permeada por discursos racistas.

Tenho pelo menos duas considerações a fazer a respeito disso. O grupo era formado por pessoas negras que reconhecem a sua ancestralidade e o tratamento estabelecido era como o de uma grande família. Isso não foi diferente com o artista da exposição, já que estávamos imersos na sua vida, por conta do trabalho educativo - o que permitiu tal intimidade. E a segunda pontuação era quanto ao modo como aquela pessoa pensava sobre os artistas, como um ser dotado de dons sobrenaturais artísticos, distantes de nós, tal como fazemos com Leonardo da Vinci, Rafael, Dalí ou qualquer outro artista de grande notoriedade.

Ao final, com mais um choque de realidade, Ronaldo afirmou que aquele era o maior grupo de pretos que ele pôde mediar; contar uma outra história. O som das palmas ecoou por todo o salão expositivo. Se íamos chamar atenção de qualquer forma, que fosse por um sinal de afeto e agradecimento.

\section{Considerações Finais}

Este texto teve como objetivo socializar algumas das minhas reflexões na participação do "Rolezão Preto", organizado pelo Setorial de Negritude de um coletivo de juventude. Ao longo do texto, tentei apresentar como a branquitude desenvolveu um lugar de vantagem estrutural, a partir do qual se forma um ethos, onde quem não está dentro daquela representação é excluído e marginalizado. Ao refletir sobre esse local, apontei como o Movimento Negro brasileiro se articulou historicamente para a luta por direitos dos negros e como, em anos 
recentes, o "rolezinho" se tornou uma ferramenta política para a ocupação de espaços por corpos marginalizados.

O "Rolezão Preto" se mostrou instrumento político atravessado por questões da negritude, que se fossem organizadas por outras pessoas ou por outras metodologias talvez não tivessem a mesma sensibilidade. Posso exemplificar: o evento estava marcado para as 14 horas, sendo um horário estratégico para quem mora longe, em especial na Baixada Fluminense, poder almoçar e ir, já que outro fator limitante é o preço dos cafés e restaurantes, não só nos museus e centros culturais, no centro da cidade.

O tempo de deslocamento, da visitação e a alimentação são elementos que também podem ser limitantes (e na maioria das vezes são) na hora de se escolher um museu ou centro cultural como atividade cultural de lazer.

Destaca-se, frequentemente, que a escola, enquanto espaço de educação formal, se constitui em espaço privilegiado de formação identitária, sendo assim lócus importante de intervenção nos rumos da construção da identidade negra. Ao não reconhecer os saberes das diversas culturas presentes no seu interior, a instituição elimina saberes e legitima as práticas hegemônicas de exclusão, pois não considera os alunos como sujeitos socioculturais frutos de diversas experiências.

Se por um lado o "rolezinho" permite a ampliação da ocupação dos espaços, mostra também que há uma crise de representação e, portanto, é imprescindível a luta por representatividade. Acredito que esse seja um dos maiores saldos que o "rolezinho" pôde proporcionar para se repensar não somente o público que tem acesso às instituições, mas também a movimentação dessa estrutura criada para nos excluir.

Nesse ponto, podemos fazer uma relação bastante simplista, dialogando com a teoria da tradução de Boaventura de Sousa Santos (2002). O que se fez é a organização de um passeio, em termos do campo do turismo. Mas o que se prestou atenção foi na ampliação das experiências ao transformar a ausência do corpo negro em presença.

Ao se traduzir os sentidos, trazemos para a ordem do dia as tensões e disputas, ocasionando a hostilidade. Para se pensar em espaços museológicos hospitaleiros, não podemos apenas olhar para os aspectos objetivos, como a qualificação dos espaços e dos profissionais, mas também para os aspectos subjetivos, já que cada público gera uma tensão no contexto de uma sociedade hierarquizada e desigual.

Mediante minha formação, estão muito evidentes os conflitos criados a partir do dualismo falso que surge entre turistas e moradores. Todavia, é preciso avançar em direção a questões de raça, gênero, classe e orientação sexual. Assim, novos elementos serão revelados e trabalhados para a diminuição das desigualdades.

Desse modo, este texto traz contribuições pragmáticas no sentido de estimular as práticas pedagógicas que visem o acesso às instituições museológicas se atentem aos aspectos 
subjetivos que cada corpo traz consigo, bem como indicar o "rolezinho" como prática metodológica para a ocupação e visitação de espaços culturais.

Como este estudo se limitou a refletir sobre a minha participação no "rolezinho", e é dessas análises contidas neste texto que novas perspectivas se desdobram na minha vida social e acadêmica, sugiro que outras investigações contemplem os aspectos subjetivos da visitação em instituições museológicas.

\section{Referências Bibliográficas}

ADAM, Tony E.; ELLIS, Carolyn; JONES, Stacy H. 2017. “Autoethnography”. In: MATTHES, J.; DAVIS, C. S.; POTTER, R. F. (Eds). The International Encyclopedia of Communication Research Methods. Hoboken: John Wiley \& Sons, p. 1-11.

BHABHA, Homi. 1998. "A outra questão: O estereótipo, a discriminação e o discurso do colonialismo”. In: BHABHA, Homi. O Local da Cultura. Belo Horizonte: EdUFMG: p.105128.

BOURDIEU, Pierre. 1989. “A identidade e a representação: Elementos para uma reflexão crítica sobre a ideia de região”. In: BOURDIEU, Pierre. O poder simbólico. Lisboa: Bertrand, p. 107137.

BRASIL. Decreto-lei no 7.967, de 18 de setembro de 1945. Dispõe sobre a Imigração e Colonização, e dá outras providências. Brasília: Casa Civil/ Subchefia de Assuntos Jurídicos. Disponível em: http://www.planalto.gov.br/ccivil_03/decreto-lei/19371946/Del7967.htm. Acesso em: 13 jun. 2021.

CALDEIRA, Teresa Pires do Rio. 2014. Qual a novidade dos rolezinhos? Espaço público, desigualdade e mudança em São Paulo. Novos Estudos, n. 98: 13-20. DOI 10.1590/S010133002014000100002

CARDOSO, Lourenço. 2014. A branquitude acrítica revisitada e a branquidade. Revista da Associação Brasileira de Pesquisadores/as Negros/as (ABPN), v. 6, n. 13: 88-106.

CARDOSO, Lourenço. 2010. Branquitude acrítica e crítica: A supremacia racial e o branco antiracista. Revista Latinoamericana de ciencias sociales, niñez y juventud, v. 8, p. 607-630.

CATOIA, Cinthia de Cassia. 2018. O Movimento Negro (1940-50) e a emergência do debate político sobre legislação antirracismo no Brasil. Café com Sociologia, v. 7, n. 1: 30-49

DAMATTA, Roberto. 1986. O que faz do brasil, Brasil? Rio de Janeiro: Rocco.

DOMINGUES, Bruno Rodrigo Carvalho. 2018. Negro na universidade, branco no trabalho de campo: reflexões sobre representação e desigualdade racial na academia. Cadernos de Campo, v. 27, n.1: 295-309. DOI 10.11606/issn.2316-9133.v27i1p295-309

FOUCAULT, Michel. 2014. A Ordem do discurso. 24. Ed. São Paulo: Edições Loyola.

GAMA, Fabiane. 2020.A autoetnografia como método criativo: experimentações com a esclerose múltipla. Anuário Antropológico, v. 45, n. 2: 188-208. DOI 10.4000/aa.5872 
GODOY, Karla Estelita. 2017. "Museus hostis, Turistas hostilis: controvérsias e caminhos para hospitalidade em instituições museológicas sob uma abordagem derridariana”. In: BRUSADIN, Leandro Benedini. (Org). Hospitalidade e Dádiva: a alma dos lugares e a cultura do acolhimento. Curitiba: Editora Prismas, pp.261-280.

MACHADO, Frederico Viana; RODRIGUES, Cristiano Santos. 2015. "Movimentos Negros e LGBT no Governo Lula: desafios da institucionalização segmentada”. In: MACHADO, Frederico Viana; MASSOLA, Gustavo Martineli; RIBEIRO, Maria Auxiliadora Teixeira (Orgs.). Estado, Ambiente e Movimentos sociais. Florianópolis: ABRAPSO Editora, p. 22-45.

MACHADO, Igor José de Renó. 2002. Mestiçagem Arqueológica. Estudos Afro-Brasileiros, n. 2, ano 24: 385-408. DOI 10.1590/S0101-546X2002000200007

PEREIRA, Amilcar Araujo. 2010. "O mundo negro": A constituição do movimento negro contemporâneo no Brasil. Tese de Doutorado. Niterói: Universidade Federal Fluminense.

RICOEUR, Paul. 1994. Tempo e Narrativa (Tomo I). Campinas: Papirus.

SANTOS, Boaventura de Sousa. 2002. Para uma sociologia das ausências e uma sociologia das emergências. Revista Crítica de Ciências Sociais, v. 63: 237-280. Disponível em: https://journals.openedition.org/rccs/1285\#quotation. Acesso em: 13 jun. 2020.

SANTOS, Silvio Matheus Alves. 2017. O método da autoetnografia na pesquisa sociológica: atores, perspectivas e desafios. PLURAL, v. 24, n .1: 214-241. DOI 10.11606/issn.21768099.pcso.2017.113972

SCHERER-WARREN, Ilse. 2014. Manifestações de rua no brasil 2013: encontros e desencontros na política. Caderno CRH, v. 27, n. 71: 417-429. DOI http://dx.doi.org/10.1590/S0103-49792014000200012

VIANA, Nildo. 2014. O significado dos rolezinhos. Revista Posição, v. 1, n. 1: 4-8.

sobre o autor

\section{Dionísio de Almeida Brazo}

Bacharel em Turismo e mestre em Cultura e Territorialidades, ambos pela Universidade Federal Fluminense.

Contribuição de Autoria: Não se aplica

Financiamento: A realização da pesquisa e escrita deste artigo contou com financiamento da Coordenação de Aperfeiçoamento de Pessoal de Nível Superior (CAPES).

Recebimento 25/10/2020

Aprovação 10/06/2021 